\section{THE INFLUENCE OF SUPERPLASTICISERS ON THE FRESH AND MECHANICAL BEHAVIOUR OF FOAM CONCRETE UTILIZING POFA AS SAND REPLACEMENT}

\author{
Abdullah Al-Shwaiter*, Hanizam Awang
}

School of Housing, Building and Planning, Universiti Sains Malaysia, Penang, Malaysia
Article history

Received

8 May 2020

Received in revised form

10 October 2020

Accepted

13 October 2020

Published online

17 December 2020

*Corresponding author hanizam@usm.my

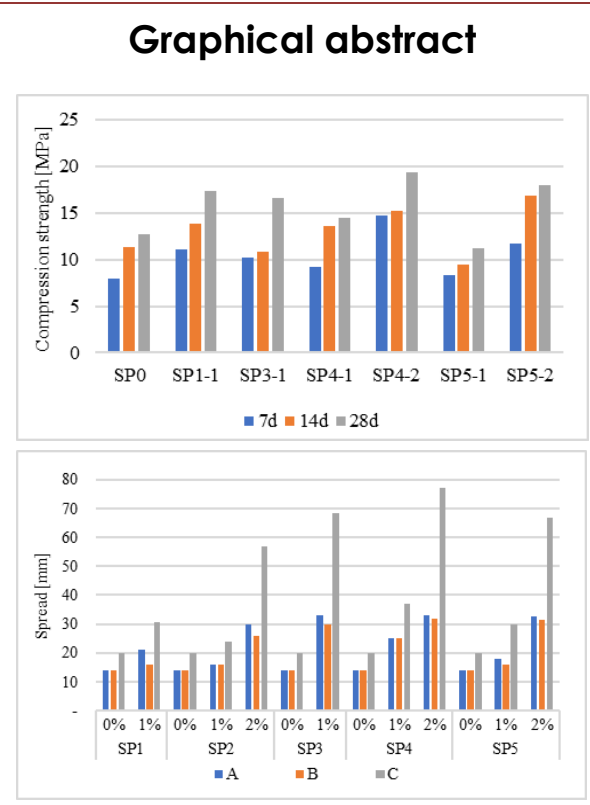

\begin{abstract}
Since the foam concrete is delicate, it is important to carefully choose the additives, such as superplasticiser (SP), to be used in this type of concrete. The effect of using different types and percentages of SP on the performance of foam concrete with target density of $1500 \pm 50 \mathrm{~kg} / \mathrm{m}^{3}$ has been investigated in this study. A sustainable material, Palm Oil fuel ash (POFA), used as a sand replacement at a level of $20 \%$ by weight. Five types of SP have been used in this study, including Sulphonated polymer-based, selected synthetic and organic polymers-based and three Polycarboxylate ether-based (PCE). Different SP contents (0.0\%, $1.0 \%$ and $2.0 \%$ ) have been used as a ratio of cement weight. Workability, consistency, foam stability and mechanical properties were investigated. The results showed that types and quantity of SP have a significant effect on the different properties of the foam concrete. Workability, compression strength and tension strength improved remarkably for most specimens. The use of $2 \%$ SP 4 , a PCE $\mathrm{SP}$, showed superior workability, compression strength and tensile strength with acceptable stability.
\end{abstract}

Keywords: Cellular concrete, superplasticiser, palm oil fuel ash, sand replacement, mechanical behaviour, workability

(C) 2021 Penerbit UTM Press. All rights reserved

\subsection{INTRODUCTION}

Owing to the enormous advantages that it offers, the interest in foam concrete has been increased. Foam concrete provides high strength to weight ratio, low density, high flowability, better thermal and acoustic isolation and lower thermal expansion [1-3]. Moreover, it reduces the weight of the construction which, in turn, reduces sections size and reinforcement quantities [4, 5]. It also reduces the production and transportation costs and facilitates the handling and fixing of the precast units [2].

Since the compaction and the vibration are not allowed in the foam concrete, the flowability of the foam concrete is a significant issue [6]. Low flowability causes the bubbles to collapse because of the stiff mixture, whereas the high flowability caused segregation which leads to collapse the bubbles as well [7]. Ling et al. 2018, [8] reported that optimum foam concrete flow, that showed the best mechanical properties, is between $20 \mathrm{~mm}$ and $25 \mathrm{~mm}$. Nambiar et al. 2008, [6] stated that $145 \%$ of spread flow is adequate workability that provides good stability for the foam mixture. Furthermore, the recommended difference between the achieved plastic density and the target plastic density is between $2 \%$ and $7 \%[9,10]$, or $\pm 50 \mathrm{~kg} / \mathrm{m}^{3}$ as suggested by other studies [11-13]. 
Superplasticiser (SP) used widely to improve the fresh and harden properties of the foam concrete. Indeed, it is important to evaluate the influence of the SP on the foam stability and on the consistency of the mixture. Although some types of SP tends to have an air-entraining function, other types have an antifoaming behaviour $[5,14]$. According to Sakai et al. 2006, [15], the SP type has a significant effect on the air content of the fresh slurry. They noticed that Polycarboxylate ether-based SP (PCE) showed a smaller size of air compared with lignosulphonate and naphthalene SP. In addition, Coppola et al. 2017, [16] stated that PCE involves a larger amount of air than naphthalene-based SP and less than phosphonatebased SP. Various types and quantities have been used in foam concrete by several researchers including PCE [11, 17-20], naphthalene-based [6, 13, 21,22 ], synthetic polymers based [23] and Sulphonate based $[24,25]$.

On the other hand, growing the palm oil use to produce biofuel generates enormous amounts of wastes. Annually about 80 million tons of dry solid biomass have been produced from the palm oil industry [26]. These materials have been burned in order to produce energy, generating palm oil fuel ash (POFA). Annually, Malaysia alone produces about 10 million tons of POFA [27]. The POFA has a relatively slow degradation which increases the damping areas and makes this problem accumulated. Additionally, the fact that these wastes are ash makes it easier to spread by the wind effect which causes pollution and several health consequences [28].

POFA has been used in concrete as an alternative of either cement or sand. Using these wastes as a sand replacement up to $8 \%$ have no significant effect on the concrete workability, as well have no effect on the compression strength [29]. Lim et al. 2013, [30] reported that replacing $20 \%$ of sand by POFA decreased the workability and enhanced the mechanical strength of foam concrete. Khalid et al. 2016, [31] mentioned that using grounded POFA as a replacement of sand showed better workability than ungrounded POFA. Moreover, the compression strength increased gradually by replacing the sand by $14 \%$ and $10 \%$ of grounded and ungrounded POFA respectively [31]. Yahaya et al. 2015, [28] noticed that both expansion and mass change resistance, of aerated concrete under sulphate attack, improved by replacing $30 \%$ of sand by POFA up to one year.

By evaluating the stability of foam, the consistency, workability and mechanical properties, the main objective of this study is to investigate the influence of different types and percentages of SP on the foam concrete behaviour. The outcomes of this comparison will provide an insight to the researchers and engineers to choose the appropriate SP type and content on the foam concrete. Moreover, this study attempts to solve the disposal problem by using row POFA as sand replacement.

\subsection{METHODOLOGY}

\subsection{Materials}

In this study, the lightweight foam concrete produced by using river sand, POFA, Portland cement, protein foam agent, regular tap water and five types of SP. Dry river sand with an oven-dry specific gravity (OD) and saturated surface dry specific gravity (SSD) equal to 2.55 and 2.61 respectively. The sand was collected from a local resource and sieved using a $1.18 \mathrm{~mm}$ sieve. Fine sand used since the large particles of sand settle in the lightweight mixture leading to collapse foam bubbles and cause segregation [32]. Sand and POFA physical properties and sieve analysis are presented in Table 1 and Figure 1 respectively. The used POFA was supplied by the United Palm Oil factory located in Penang, Malaysia. Sieving row POFA through sieve $1.18 \mathrm{~mm}$ has been done to ensure that POFA does not contain any coarse or unburned particles and to be as the size range as sand. Specific gravity and water absorption ratio of sand and POFA were determined based on ASTM- C128 2001, [33]. The results of the X-ray fluorescence (XRF) analysis of POFA and cement are shown in Table 2. The microstructure of the used POFA tested by the scanning electron microscope (SEM) with a magnification of 70 times ( Figure 2).

Table 1 Fillers physical properties

\begin{tabular}{ccc}
\hline Physical property & Sand & POFA \\
\hline Specific gravity (OD) & 2.55 & 1.97 \\
Specific gravity (SSD) & 2.61 & 2.06 \\
Absorption \% & 2.25 & 4.38 \\
D10 mm & 0.20 & 0.20 \\
D30 mm & 0.50 & 0.50 \\
D60 mm & 0.85 & 0.85 \\
Cu = D60/D10 & 4.25 & 4.25 \\
Cc = D30 2 /(D10 x D60) & 1.47 & 1.47 \\
\hline Cu: Uniformity coefficient; Cc: Coefficient of curvature
\end{tabular}

Ordinary Portland cement complying with the specification of BS EN 197-1 2011, [34] has been used. The cement strength grade is $52.5 \mathrm{MPa}$ and the chemical properties are presented in Table 2. A liquid protein foam locally produced with a trademark (NORAITE PA-1) was used. Five types of superplasticisers with various chemical compositions and different trademarks have been used in this study.

Table 3 presents the chemical-based and the physical properties of the used SPs. 


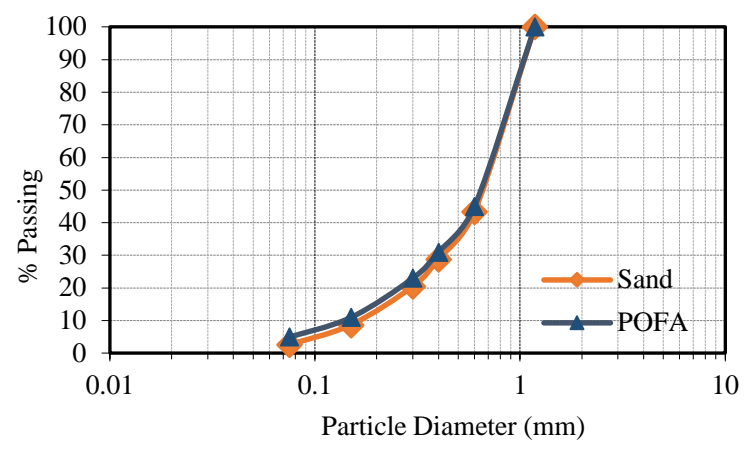

Figure 1 Sieve analysis of POFA and sand

Table 2 Chemical composition of POFA and cement

\begin{tabular}{llllllllllll}
\hline Material & SiO2* & TiO2 & Al2O3* & Fe2O3* & MnO & MgO & CaO & Na2O & K2O & P2O5 & $\Sigma\left(^{*}\right)$ \\
\hline POFA & 61.68 & 0.28 & 4.46 & 6.89 & 0.17 & 3.91 & 9.37 & 0.23 & 7.76 & 5.24 & 73.03 \\
Cement & 20.34 & 0.17 & 5.22 & 3.38 & 0.03 & 1.24 & 56.60 & 0.12 & 0.62 & 0.02 & 28.94 \\
\hline
\end{tabular}

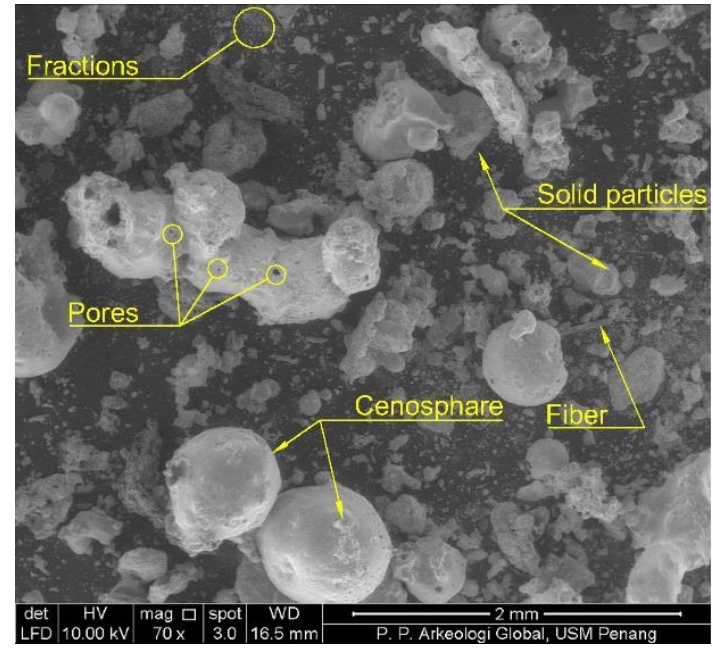

Figure 2 The microstructure of POFA

\subsection{Mix Proportions}

In this study, foam concrete produced with a target density of $1500 \mathrm{~kg} / \mathrm{m}^{3}$ by using constant cement-sand ratio 1:2 by weight. Twenty per cent of POFA and eighty per cent of sand, by weight, used as filler. The minimum percentage of water-cement ratio (W/C) required for fully hydration found to be 0.5 for the referenced specimen. This ratio is relatively high since the high absorption of POFA. The W/C ratio kept constant for all mixes in order to guarantee the ability to investigate the influence of the SPs. Eleven mixtures produced by using five types of SP with two contents along with referenced specimens. The contents of SP were $0.0 \%$, as referenced specimen, $1.0 \%$ and $2.0 \%$ of cement weight. The mixes properties are listed in Table 4.

\subsection{Production and Curing}

The foam concrete laboratory produced by using a vertical shaft mixer. Cement, sand, POFA and water mixed, then the specified type and quantity of SP added to the ready mixed concrete. The pre-foamed method used to produce the foam by diluting the foaming agent in water with a ratio of 1:30 by weight. The resulting solution and compressed air mixed by foam generator to produce foam with a density of $65 \pm 3 \mathrm{~kg} / \mathrm{m}^{3}$. The foam used directly to avoid the loss of stability and viscosity. Foam concrete fresh density maintained to be about $1630 \mathrm{~kg} / \mathrm{m}^{3}$, to ensure that foam concrete hard density is within the desirable range, $1500 \pm 50 \mathrm{~kg} / \mathrm{m}^{3}$. After casting, the specimens covered by a plastic sheet for 24 hours to prevent any moisture loss. Sealing curing applied by covering the samples by polythene sheet after 24 hours until the testing age.

\subsection{Properties Measurements}

Two methods used to evaluate the workability, slump flow test and spreadability test. The slump flow test has been done according to ASTM C 1611/C 1611M 2005, [35] by placing a sample of fresh concrete, without compacting or vibrating, inside the cone. Two diameters were measured, and the average value was taken. Meanwhile, to test the spreadability of the foam concrete, an open-ended cylinder with diameter and height equal to $107 \mathrm{~mm}$ placed on $400 \times 400 \mathrm{~mm}$ steel plate and two perpendicular diameters were taken after raising the cylinder vertically. The evaluation of the mix stability conducted by calculating the ratio of the actual foam weight that added until target elastic density achieved to the calculated foam weight. Meanwhile, the consistency of the fresh mixture estimated by measuring the ratio of the fresh density to the designated density. 
Cubes with dimensions of $100 \times 100 \times 100 \mathrm{~mm}$ prepared and tested in accordance with BS-EN-12390-3 2009, [36] using a hydraulic compression machine with a capacity of $3000 \mathrm{KN}$. Samples tested at a loading rate of $0.6 \mathrm{MPa} / \mathrm{sec}$. A total number of 99 cubes tested at age of 7,14 and 28 days. The average value of three specimens was taken. The flexural strength evaluated by using prism with dimensions of $160 \times 160 \times 40 \mathrm{~mm}$ in accordance with BS-EN-12390-5 2009, [37]. A concentrated load was subjected to the mid-span of the specimens after 28 days and the average value of three specimens was taken. The Splitting tensile strength tested according to BS-EN-12390-6 2009, [38] by preparing simples with $100 \mathrm{~mm}$ diameter and 200 $\mathrm{mm}$ length under loading rate of $0.05 \mathrm{MPa} / \mathrm{sec}$. Three specimens tested for each mix at 28 days and the average value was taken.

Table 3 Superplasticisers properties

\begin{tabular}{lllll}
\hline Symbol & Chemical composition & Trademark & Specific gravity & Colour \\
\hline SP1 & Sulphonated polymer-based & MasterRheobuild 1100M & 1.19 & Dark brown \\
SP2 & Selected synthetic and organic & Conplast SP2000 & 1.22 & Dark brown \\
& polymers based & MasterGlenium 393 & 1.04 & Yellowish-brown \\
SP3 & PCE based & MasterGlenium ACE 8109 & 1.03 & Brown \\
SP4 & PCE based & MasterGlenium SKY 8788 & 1.08 & Dark brown \\
SP5 & PCE based & & & \\
\hline
\end{tabular}

Table 4 The mix proportion of the foam concrete

\begin{tabular}{|c|c|c|c|c|c|c|c|c|}
\hline Symbol & $\begin{array}{l}\text { Cement } \\
\mathrm{kg} / \mathrm{m}^{3}\end{array}$ & $\begin{array}{l}\text { Sand } \\
\mathrm{kg} / \mathrm{m}^{3}\end{array}$ & $\begin{array}{l}\text { POFA } \\
\mathrm{kg} / \mathrm{m}^{3}\end{array}$ & $\begin{array}{l}\text { Water } \\
\mathrm{kg} / \mathrm{m}^{3}\end{array}$ & $\begin{array}{l}\text { SP } \\
\%\end{array}$ & $\begin{array}{l}\mathrm{SP} \\
\mathrm{kg} / \mathrm{m}^{3}\end{array}$ & $\begin{array}{l}\text { Spreadability } \\
\mathrm{mm}\end{array}$ & $\begin{array}{l}\text { Slump flow } \\
\mathrm{mm}\end{array}$ \\
\hline SPO & 468.3 & 749.3 & 187.3 & 234.2 & $0 \%$ & 0 & 14 & 20 \\
\hline SP1-1 & 468.3 & 749.3 & 187.3 & 234.2 & $1 \%$ & 0.47 & 16 & 31 \\
\hline SPI-2 & 468.3 & 749.3 & 187.3 & 234.2 & $2 \%$ & 0.94 & - & - \\
\hline SP2-1 & 468.3 & 749.3 & 187.3 & 234.2 & $1 \%$ & 0.47 & 16 & 24 \\
\hline SP2-2 & 468.3 & 749.3 & 187.3 & 234.2 & $2 \%$ & 0.94 & 26 & 69 \\
\hline SP3-1 & 468.3 & 749.3 & 187.3 & 234.2 & $1 \%$ & 0.47 & 30 & 69 \\
\hline SP3-2 & 468.3 & 749.3 & 187.3 & 234.2 & $2 \%$ & 0.94 & - & - \\
\hline SP4-1 & 468.3 & 749.3 & 187.3 & 234.2 & $1 \%$ & 0.47 & 24 & 37 \\
\hline SP4-2 & 468.3 & 749.3 & 187.3 & 234.2 & $2 \%$ & 0.94 & 32 & 77 \\
\hline SP5-1 & 468.3 & 749.3 & 187.3 & 234.2 & $1 \%$ & 0.47 & 16 & 30 \\
\hline SP5-2 & 468.3 & 749.3 & 187.3 & 234.2 & $2 \%$ & 0.94 & 32 & 70 \\
\hline
\end{tabular}

\subsection{RESULTS AND DISCUSSION}

\subsection{The Properties of POFA}

The row POFA consists of a considerable amount of unburned and large materials which affect the stability of the fresh mixture and the hardened properties of the foam concrete. Therefore, POFA is usually sieved using $300 \mu \mathrm{m}$ or less in order to be used as a cement replacement [39]. In this study, the POFA sieved using $1.18 \mathrm{~mm}$ to remove the unburned and large particles. The remaining waste, after sieving POFA with $1,18 \mathrm{~mm}$, is approximately $33 \%$ of the total disposal compared with $81 \%$ for sieved POFA using 300 $\mu \mathrm{m}$. In addition, the use of POFA as a sand replacement enables higher amounts of POFA to be recycled as the sand content in concrete is higher than cement.

Table 2 showed that the used POFA contains a high percentage of silicon dioxide (61.68\%), meanwhile, the total of silicon dioxide, aluminium oxide and iron oxide is $73.03 \%$. This makes the used POFA chemically meets the pozzolanic requirements of class-N and F of ASTM C618 2005, [40]. This results in a higher formation of $\mathrm{C}-\mathrm{S}-\mathrm{H}$ which enhance the strength of the concrete [30]. However, since the used
POFA is ungrounded, the effect of the pozzolanic reaction is relatively small because the fineness of the silicon dioxide directly affects its reactivity [41, 42].

From Figure 2, it can be observed that POFA contains angular, porous and solid particles, fibres and fractions. The high content of angular and porous particles explains the high absorption and the low specific gravity shown by POFA (Table 1) and predicts an increase in the water demand and reduction on the workability of the fresh mixture.

\subsection{Density and Volumetric Foam Stability}

The measurements of the foam concrete density were conducted for fresh mixture before adding the foam (mortar) and after adding the foam (fresh), as well for hard density (Table 5). As shown there, both type and percentage of the SP remarkably influence the amount of entered air to the mortar. In spite of SP4$1.0 \%$ which showed excessive air entrainment (more than $20 \%$ ), using $1.0 \%$ of SP decreased the mortar density by approximately $4.3 \%$, although using $2 \%$ of $\mathrm{SP}$ increases the mortar density by an average of $5.8 \%$ compared with SPO. The reduction of the density, by using $1.0 \%$ of SP, confirms the findings of Alaka et al. 2016, [43] and Łaźniewska et al. 2012, [44]. However, 
increasing the density by using $2.0 \%$ of SP occurred due to the high increase in the dispersity of the fine grains which increases the packing density [45].

The results also indicated that the use of SP2 (selected synthetic and organic polymer-based) leads to collapse the foam bubbles, which explain the increase in their hard density to more than $1500 \mathrm{~kg} / \mathrm{m}^{3}$. The use of $1 \%$ and $2 \%$ SP2 lead resulted in partially and fully collapse of the foam bubbles, respectively. Thereby, all specimens showed good consistency, close to 1.0, except for SP2 which showed relatively high values equal to 1.09 and 1.25 for $1.0 \%$ and $2.0 \%$ respectively. For these specimens, the collapsible foam formed a thin layer, approximately $2 \mathrm{~mm}$, over the concrete (Figure 3). In contrast with SP2, SP5-1 has a high foaming behaviour by entering an excessive amount of air to the concrete which reduced the hard density to $1366 \mathrm{~kg} / \mathrm{m}^{3}$ without using any amount of foam. For other specimens, the hard densities fall in the targeted range, $1500 \pm 50 \mathrm{~kg} / \mathrm{m}^{3}$.

As mentioned earlier, the ratio of the actual to calculated foam volume, that is required to reach the target density within the range of $\pm 50 \mathrm{~kg} / \mathrm{m}^{3}$, used to estimate the loosing of the foam during the mixing process (the foam stability). The results of the actual foam, calculated foam and foam stability are presented in Table 5. As shown there, the SP type has an apparent influence on the stability of the foam. For specimens that did not attain the targeted density, namely (SP2-1, SP2-2 and SP5-1), the foam stability was unmeasurable.

Table 5 Mix densities and foam quantities

\begin{tabular}{|c|c|c|c|c|c|c|c|c|}
\hline Specimens & SP\% & $\begin{array}{l}\text { Mortar density } \\
\mathrm{kg} / \mathrm{m}^{3}\end{array}$ & $\begin{array}{l}\text { Fresh } \\
\text { density } \\
\mathrm{kg} / \mathrm{m}^{3}\end{array}$ & $\begin{array}{l}\text { Hard } \\
\text { density } \\
\mathrm{kg} / \mathrm{m}^{3}\end{array}$ & Consistency & $\begin{array}{l}\text { Act. foam } \\
\mathrm{kg} / \mathrm{m}^{3}\end{array}$ & $\begin{array}{l}\text { Cal. } \\
\text { Foam } \\
\mathrm{kg} / \mathrm{m}^{3}\end{array}$ & $\begin{array}{l}\text { Act. } \\
\text { /Cal. } \\
\text { Foam }\end{array}$ \\
\hline SPO & $0 \%$ & 1887 & 1648 & 1492 & 1.01 & 12.17 & 8.54 & 1.43 \\
\hline SP1-1 & $1 \%$ & 1830 & 1652 & 1537 & 1.01 & 9.04 & 7.92 & 1.14 \\
\hline SP1-2 & $2 \%$ & Segregation & - & - & - & - & - & - \\
\hline SP2-1 & $1 \%$ & 1804 & 1778 & 1679 & 1.09 & - & 2.56 & $N / A$ \\
\hline SP2-2 & $2 \%$ & 2045 & 2045 & 1972 & 1.25 & - & 9.90 & $N / A$ \\
\hline SP3-1 & $1 \%$ & 1827 & 1580 & 1462 & 0.97 & 5.12 & 6.52 & 0.79 \\
\hline SP3-2 & $2 \%$ & Segregation & - & - & - & - & - & - \\
\hline SP4-1 & $1 \%$ & 1750 & 1644 & 1505 & 1.01 & 4.30 & 3.60 & 1.19 \\
\hline SP 4-2 & $2 \%$ & 1976 & 1630 & 1533 & 1.00 & 15.77 & 8.00 & 1.97 \\
\hline SP5-1 & $1 \%$ & 1812 & 1485 & 1366 & 0.91 & 0.00 & 0.00 & $\mathrm{~N} / \mathrm{A}$ \\
\hline SP5-2 & $2 \%$ & 1970 & 1615 & 1495 & 0.99 & 8.21 & 7.83 & 1.05 \\
\hline
\end{tabular}

Otherwise, the foam stability showed good results, close to 1.0, except for SPO and SP4-2\% which showed relatively high ratios. This occurred because SPO showed low workability which makes the mixture cohesive. In contrast, SP4-2 showed a high flowability. This, in turn, leads to breaking some of the foam bubbles during the mixing process in both cases (the cohesive and high flowable mixture). Meanwhile, adding 2\% SP1 and SP3 caused segregation which also caused to loss of the foam bubble because of the weak holding of the mixture. These results confirm the findings of Nambiar et al. 2006, [46] who noticed that stiff mixture and high $\mathrm{w} / \mathrm{c}$ increased the foam concrete density due to collapsing the foam bubbles.
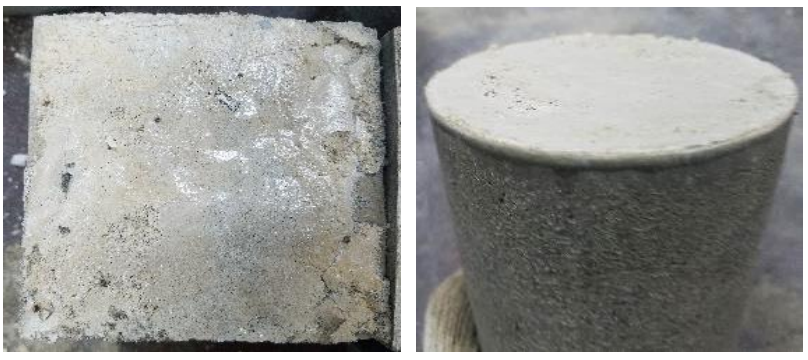

Figure 3 Collapsible foam layer

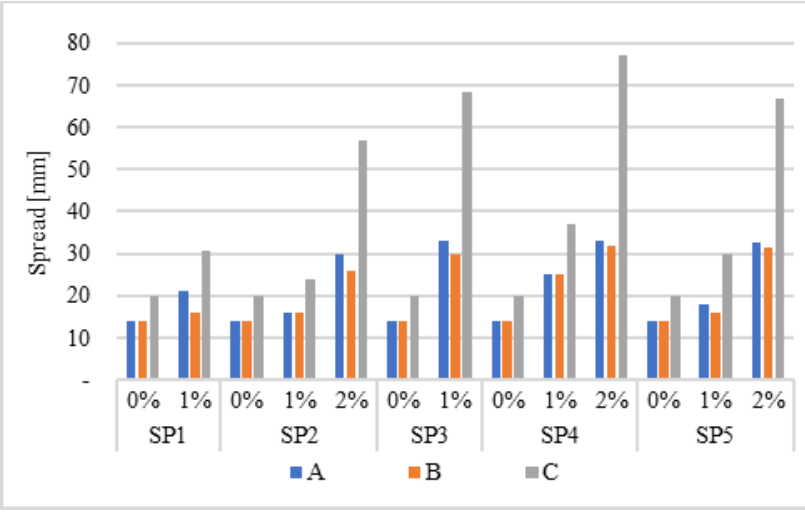

Where

A: spreadability before adding the foam; B: spreadability after adding the foam; C slump flow.

Figure 4 Spreadability and slump flow results

\subsection{Workability}

The results of slump flow and spreadability teste, before and after adding the foam, are given in Figure 4. As could be seen, there is no clear relation between slump flow and spreadability has been found, however, both of which gives a good indicator for the workability properties of the foam concrete. 
As expected, the use of a superplasticiser with a fixed water content improved the workability of all mixtures compared to the referenced specimens. The reference specimen showed poor workability behaviour, while the workability of the specimens with SP differs depends on the SP type and dosage. The slump flow of specimens with SP ranged between 24 and $77 \mathrm{~mm}$ by increasing about (20\% and 285\%), however, the spreadability was between 16 and 33 $\mathrm{mm}$ by increasing about (14\% and $136 \%$ ). Adding the foam to the mixture leads to a slight reduction on spreadability in most cases. This occurred since adding the foam reduce the mortar weight and increase the cohesion between the bubbles and the solid particles which confirms the results of Nambiar et al. 2008, [6] and Karl et al. 1993, [47].

\subsection{Compression Strength}

The compression strength of the foam concrete specimens with several SP types and dosages after 7 , 14 and 28 days of sealing curing are shown in Table 6 . It can be seen that compression capacity increased for all specimens with age. As well, using SP leads to a significant improvement in the compression strength of foam concrete. This improvement differs based on the SP type and dosage which shows a good agreement with previous findings of Mangane et al. 2018, [48] who reported an increase in compression strength after 28 days for several SP types under fixed W/C. In addition, the SP content of the same type showed an improvement in the compression strength.

Table 6 Mechanical behaviour

\begin{tabular}{lllllll}
\hline SP type & SP\% & \multicolumn{2}{l}{ Compression [MPa] } & Tension [MPa] & \multicolumn{2}{l}{ Flexural [MPa] } \\
& & $\mathbf{7 d}$ & $\mathbf{1 4 d}$ & $\mathbf{2 8 d}$ & $\mathbf{2 8 d}$ & $\mathbf{2 8 d}$ \\
\hline SP0 & $0.0 \%$ & 7.9 & 11.3 & 12.7 & 0.9 & 4.3 \\
SP1-1 & $1.0 \%$ & 11.1 & 13.8 & 17.3 & 1.2 & 4.2 \\
SP1-2 & $2.0 \%$ & Segregation & - & - & - & - \\
SP2-1 & $1.0 \%$ & 13.1 & 20.2 & 22.6 & 1.5 & 8.1 \\
SP2-2 & $2.0 \%$ & 34.9 & 36.5 & 44.2 & 2.4 & 10.4 \\
SP3-1 & $1.0 \%$ & 10.2 & 10.9 & 16.7 & 1.0 & 5.0 \\
SP3-2 & $2.0 \%$ & Segregation & - & - & - & \\
SP4-1 & $1.0 \%$ & 9.2 & 13.6 & 14.4 & 1.1 & 3.4 \\
SP4-2 & $2.0 \%$ & 14.7 & 15.2 & 19.4 & 1.4 & 5.3 \\
SP5-1 & $1.0 \%$ & 8.27 & 9.47 & 11.2 & 0.89 & 2.7 \\
SP5-2 & $2.0 \%$ & 11.7 & 16.8 & 18.0 & 1.8 & 5.0 \\
\hline
\end{tabular}

This occurred since increasing the SP enhances the ability to optimize and redistribute the large pores in the slurry and the pores become more uniform than before. This finding is in line with the results of Wu et al. 2020, [49], who noticed a significant increase in compression strength gradually with increasing the SP content from 1.0\% to $2.0 \%$.

The anti-foaming behaviour that SP2 showed, caused a remarkable increase in the density which, in turn, lead to an increase in the compression strength as expected. Figure 5 presents the compression strength of the specimens that attained the target density. As could be seen there, the increasing of the compression strength due to increasing the age and SP content has no predictable pattern and depend mainly on the SP type and content. At 28 days, SP4 (PCE) with $2.0 \%$ SP showed the superior compression strength which is equal to $19.4 \mathrm{MPa}$. Also, the improvement in the strength was equal to $85 \%, 35 \%$ and $53 \%$ compared with SPO at the ages of 7,14 and 28 days, respectively. On the other hand, at the level of 1.0\% SP, SPI (sulphonated polymer-based) showed the highest compression strength $(17.3 \mathrm{MPa})$ by an increasing equal to $36 \%$ at 28 days compared with SPO.

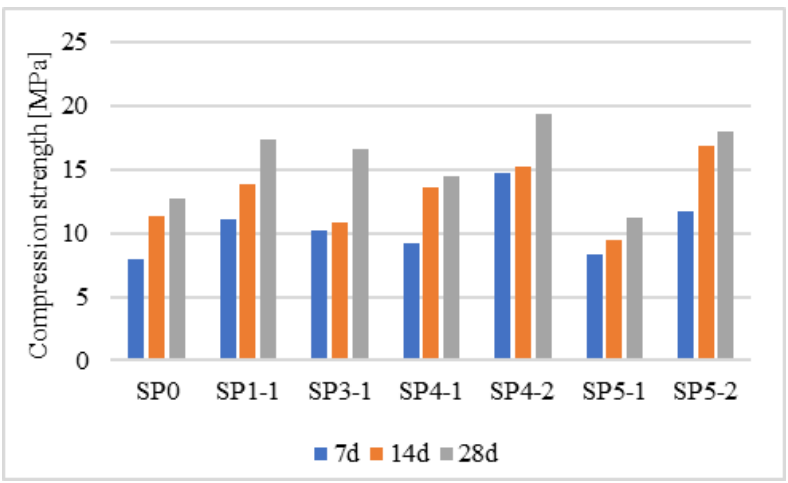

Figure 5 The compression strength of specimens that attain the target density

\subsection{Tension Strength}

The splitting tensile strength test carried out after 28 days of sealing curing. Table 6 presents the results of the tensile strength for all specimens while the splitting 
tensile strength for the specimens that meet the target density is presented in Figure 6 with the increasing values compared to SPO. As seen there, using the SP showed an increase in the splitting tensile strength for all specimens except for SP5-1 which showed a reduction due to its low density. The splitting tensile strength for specimens with SP was approximately between 1.0 and $1.8 \mathrm{MPa}$ at 28 days compared with $0.9 \mathrm{MPa}$ for the referenced specimen. In addition, the splitting tensile strength and compression strength have no direct relation. For an instant, SP4-2 showed the highest compression strength, however, SP5-2\% showed the highest splitting tensile strength. This finding shows a good agreement with the previous studies of $[24,43]$.

On the other hand, the specimens that didn't attain the target density, either due to the antifoaming tendency or the highly air-entertainer behaviour of the SP, showed a relative splitting tensile strength with the density. This has occurred because an increase in the density of foam concrete leads to an increase in mechanical behaviour [18, 50, 51]. Equation (1) that suggested by Shafigh et al. 2010, [52], gives an acceptable estimation for the tensile strength and could be used for foam concrete contain POFA as sand replacement.

$$
f_{t}=0.2^{2} \sqrt{f_{c u}^{2}}
$$

Where: $f_{+}=28$ days splitting tensile strength (MPa) and $f_{C u}=28$ days compression strength (MPa).

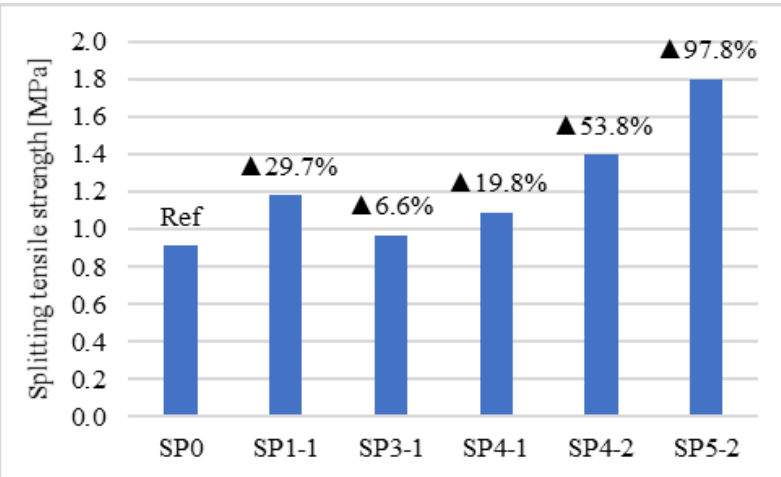

Figure $\mathbf{6}$ Tensile splitting tensile strength of specimens that attain the target density

\subsection{Flexural Strength}

The results of the flexural strength of the foam concrete after 28 days of seal curing are presented in Table 6 for the different types and contents of SP. The flexural strength for the specimen that reached the target density was in the range of 3.4 and $5.3 \mathrm{MPa}$, as presented in Figure 7. As could be seen there, SP4-2 showed the superior flexural strength by an increase of about $29.1 \%$ compared to the reference specimen. While using $1.0 \%$ of SP 4 showed less flexural strength by a reduction of about $35 \%$ compared with using $2.0 \%$ of the same type of SP.

Unlike the splitting tensile strength, using SP did not improve the flexural strength for all the specimens. Indeed, the referenced specimens showed a flexural strength equal to $4.3 \mathrm{MPa}$ which is higher than SP1-1 and SP4-1 which showed flexural strength equal to 4.2 and 3.8 MPa, respectively. Otherwise, similar to compression and tensile strength for the specimens that didn't attain the target density, the flexural strength increased gradually with increasing the hard density.

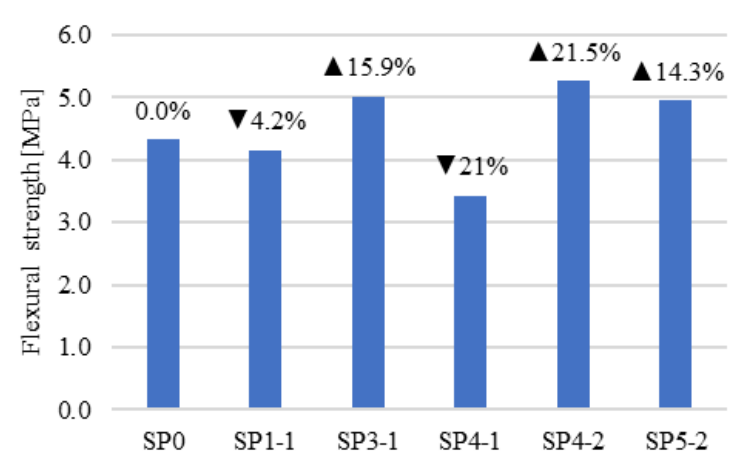

Figure 7 Flexural strength of specimens that attain the target density

\subsection{CONCLUSIONS}

This study shed light on the influence of several types and different percentages of superplasticiser on the foam concrete behaviour with a density of $1500 \pm 50$ $\mathrm{kg} / \mathrm{m}^{3}$. POFA was used as a partial replacement of sand at a level of $20 \%$. The use of POFA as a filler enables larger particles and higher quantities of POFA to be recycled, which have better environmental impacts than the use of POFA as a binder.

The result of this investigation confirms that using SP has a remarkable improvement on the workability and mechanical behaviour of the foam concrete. The improvement in the slump-flow was between $20 \%$ and $285 \%$, however, it was between $14 \%$ and $136 \%$ for the spreadability. The selected synthetic and organic polymers-based SP (SP2) exhibited an anti-foaming behaviour leading the foam bubbles to partially and fully collapse by using $1.0 \%$ and $2.0 \%$, respectively. Regardless of SP2, using $1.0 \%$ of other SPs produces a stable mixture with remarkable air inclusion for all mixtures. SP5 entered an excessive amount of air that lowered the density below the target density. However, using $2 \%$ of SP increase the mortar density, increase the foam demand and increases the possibility of segregation to occur. The segregation occurred by using $2.0 \%$ of SP1 and SP3.

Overall, SP4 (PCE) showed superior workability, compression strength and flexural strength in comparison with all specimens. Moreover, it showed a stable mixture at high contents and entered an 
acceptable amount of air to produce foam concrete with densities up to $1600 \mathrm{~kg} / \mathrm{m}^{3}$.

\section{Acknowledgements}

The authors gratefully acknowledge the University Sains Malaysia for providing financial support to this research through the USM RUI Grant Ref. No. $1001 / P P B G N / 8014015$.

\section{References}

[1] Hamad, A. J. 2014. Materials, Production, Properties and Application of Aerated Lightweight Concrete: Review. International Journal of Materials Science and Engineering. 2.

[2] Amran, Y. M., N. Farzadnia, and A. A. Ali. 2015. Properties and Applications of Foamed Concrete: A Review. Construction and Building Materials. 101: 990-1005.

[3] A. Just and B. Middendorf. 2009. Microstructure of Highstrength Foam Concrete. Mater. Charact. 60(7): 741-748.

[4] Hulimka, J., R. Krzywoń, and A. Jędrzejewska. 2017. Laboratory Tests of Foam Concrete Slabs Reinforced with Composite Grid. Procedia Engineering. 193: 337-344.

[5] Zhang, Z., et al. 2014. Geopolymer Foam Concrete: An Emerging Material for Sustainable Construction. Construction and Building Materials. 56: 113-127.

[6] Nambiar, K. E. K. and K. Ramamurthy. 2008. Fresh State Characteristics of Foam Concrete. Journal of Materials in Civil Engineering. 20(2): 111-117.

[7] Raj, A., D. Sathyan, and K. M. Mini. 2019. Physical and Functional Characteristics of foam Concrete: A Review. Construction and Building Materials. 221: 787-799.

[8] Ling, P. C. H., et al. 2018. Mechanical Properties of Lightweight Foamed Concrete Using Polycarboxylate Ether Superplasticizer. IOP Conference Series: Materials Science and Engineering. 431 (6): 062008.

[9] Narayanan, N. 1999. Influence of Composition on the Structure and Properties of Aerated Concrete. IIT Madras, June.

[10] Mellin, P. 1999. Development of Structural Grade Foamed Concrete. MSc Dissertation. University of Dundee.

[11] She, W., et al. 2018. Application of Organic-and Nanoparticle-modified Foams in Foamed Concrete: Reinforcement and Stabilization Mechanisms. Cement and Concrete Research. 106: 12-22.

[12] Jones and A. McCarthy. 2005. Utilising Unprocessed LowLime Coal Fly Ash in Foamed Concrete. Fuel. 84(11): 13981409.

[13] Chandni, T. J. and K. B. Anand. 2018. Utilization of Recycled Waste as Filler in Foam Concrete. Journal of Building Engineering. 19: 154-160.

[14] Łazniewska-Piekarczyk, B. and J. Szwabowski. 2012. The Influence of the Type of Anti-Foaming Admixture and Superplasticizer on the Properties of Self-Compacting Mortar and Concrete. Journal of Civil Engineering and Management. 18(3): 408-415.

[15] Sakai, E., et al. 2006. Influence of Superplasticizers on the Hydration of Cement and the Pore Structure of Hardened Cement. Cement and Concrete Research. 36(11): 20492053.

[16] Coppola, L., et al. 2017. Performance and Compatibility of Phosphonate-based Superplasticizers for Concrete. Buildings. 7(3): 62.

[17] Gökçe, H. S., D. Hatungimana, and K. Ramyar. 2019. Effect of Fly Ash and Silica Fume on Hardened Properties of Foam Concrete. Construction and Building Materials. 194: 1-1 1.

[18] Liu, M. Y. J., et al. 2014. Evaluation of Thermal Conductivity, Mechanical and Transport Properties of Lightweight
Aggregate Foamed Geopolymer Concrete. Energy and Buildings. 72: 238-245.

[19] Pan, Z., H. Li, and W. Liu. 2014. Preparation and Characterization of Super Low Density Foamed Concrete From Portland Cement and Admixtures. Construction and Building Materials. 72: 256-261.

[20] Hilal, A. A. 2015. Properties and Microstructure of Preformed Foamed Concretes. PhD Thesis. University of Nottingham.

[21] Ma, C. and B. Chen. 2016. Properties of Foamed Concrete Containing Water Repellents. Construction and Building Materials. 123: 106-114.

[22] Cong, M. and C. Bing. 2015. Properties of a Foamed Concrete with Soil as Filler. Construction and Building Materials. 76: 61-69.

[23] Falliano, D., et al. 2018. Experimental Investigation on the Compressive Strength of Foamed Concrete: Effect of Curing Conditions, Cement Type, Foaming Agent and Dry Density. Construction and Building Materials. 165: 735-749.

[24] Hanizam, A., et al. 2014. Utilisation of Oil Palm Ash in Foamed Concrete. MATEC Web of Conferences. 15:01033.

[25] Awang, H., et al. 2014. The Mechanical Properties of Foamed Concrete containing Un-processed Blast Furnace Slag. MATEC Web of Conferences. EDP Sciences.

[26] Samiran, N. A., et al. 2016. Progress in Biomass Gasification Technique-with focus on Malaysian Palm Biomass for Syngas Production. Renewable and Sustainable Energy Reviews. 62: 1047-1062.

[27] Hamada, H. M., et al. 2018. The Present State of the Use of Palm Oil Fuel Ash (POFA) in Concrete. Construction and Building Materials. 175: 26-40.

[28] Yahaya, F. M., K. Muthusamy, and M. W. Hussin. 2015. Long Term Investigation on Sulphate Resistance of Aerated Concrete Containing Palm Oil Fuel Ash. ARPN Journal of Engineering and Applied Sciences. 11: 2406-2411.

[29] Wan Ahmad, S., et al. 2017. Properties of Concrete Containing Unground Palm Oil Fuel Ash as Partial Sand Replacement. Applied Mechanics and Materials. 864: 278283.

[30] Lim, S. K., et al. 2013. Fresh and Hardened Properties of Lightweight Foamed Concrete with Palm Oil Fuel Ash as Filler. Construction and Building Materials. 46: 39-47.

[31] Khalid, N. H. A., et al. 2016. Palm Oil Fuel Ash as Potential Green Micro-Filler in Polymer Concrete. Construction and Building Materials. 102: 950-960.

[32] Panesar, D. 2013. Cellular Concrete Properties and the Effect of Synthetic and Protein Foaming Agents. Construction and Building Materials. 44: 575-584.

[33] ASTM- C128. 2001. Standard Test Method for Specific Gravity and Absorption of.

[34] BS EN 197-1. 2011. Cement - Part 1: Composition, Specifications and Conformity Criteria for Common Cements. BSI Standards Publication.

[35] C 1611/C 1611M, Standard Test Method for Slump Flow of Self-Consolidating Concrete. 2005, ASTM.

[36] BS-EN-12390-3. 2009. Testing Concrete -Part 116: Method for Determination of Compressive Strength of Concrete Cubes.

[37] BS-EN-12390-5. 2009. Testing Hardened Concrete Part 5: Flexural Strength of Test Specimens.

[38] BS-EN-12390-6. 2009. Testing Hardened Concrete Part 6: Tensile Splitting Strength of Test Specimens.

[39] Chandara, C., et al. 2010. The Effect of Unburned Carbon in Palm Oil Fuel Ash on Fluidity of Cement Pastes Containing Superplasticizer. Construction and Building Materials. 24(9): 1590-1593.

[40] C618, A. 2005. Standard Specification for Coal Fly Ash and Raw or Calcined Natural Pozzolan for Use in Concrete.

[41] Chauhan, R. and A. Kumar. 2013. Radon Resistant Potential of Concrete Manufactured Using Ordinary Portland Cement Blended with Rice Husk Ash. Atmospheric Environment. 81: 413-420.

[42] Sanjuan, M. A., et al. 2015. Effect of Silica Fume Fineness on the Improvement of Portland Cement Strength 
Performance. Construction and Building Materials. 96: 5564.

[43] Alaka, H. A., L. O. Oyedele, and O. L. Toriola-Coker. 2016. Effect of Excess Dosages of Superplasticizer on the Properties of Highly Sustainable High-volume Fly Ash Concrete. International Journal of Sustainable Building Technology and Urban Development. 7(2): 73-86.

[44] Łaźniewska, P. B. and J. Szwabowski. 2012. The Influence of the Type of Anti-foaming Admixture and Superplasticizer on the Properties of Self-compacting Mortar and Concrete. Journal of Civil Engineering and Management. 18(3): 408415.

[45] Kismi, M., J.-C. Saint-Arroman, and P. Mounanga. 2012. Minimizing Water Dosage of Superplasticized Mortars and Concretes for a Given Consistency. Construction and Building Materials. 28(1): 747-758.

[46] Nambiar, E. K. and K. Ramamurthy. 2006. Influence of Filler Type on the Properties of Foam Concrete. Cement and Concrete Composites. 28(5): 475-480.

[47] Karl, S. and J. Worner. 1993. Foamed Concrete-Mixing and Workability. Special Concrete-workability and Mixing. E\&FN Spon London. 217-224.
[48] Mangane, M. B. C., et al. 2018. Influence of Superplasticizers on Mechanical Properties and Workability of Cemented Paste Backfill. Minerals Engineering. 116:3-14.

[49] Wu, R., et al. 2020. Utilization of the Circulating Fluidized Bed Combustion Ash in Autoclaved Aerated Concrete: Effect of Superplasticizer. Construction and Building Materials. 237: 117644

[50] Wongkeo, W. and A. Chaipanich. 2010. Compressive Strength, Microstructure and Thermal Analysis of Autoclaved and Air Cured Structural Lightweight Concrete Made with Coal Bottom Ash and Silica Fume. Materials Science and Engineering: A. 527(16-17): 3676-3684.

[51] Ma, C. and B. Chen. 2017. Experimental Study on the Preparation and Properties of a Novel Foamed Concrete Based on Magnesium Phosphate Cement. Construction and Building Materials. 137: 160-168.

[52] Shafigh, P., M. Z. Jumaat, and H. Mahmud. 2010. Mix Design and Mechanical Properties of Oil Palm Shell Lightweigh Aggregate Concrete: A Review. International Journal of the Physical Sciences. 5(14): 2127-2134. 